\title{
La tierra prometida. Representaciones de Andalucía a través de la promoción turística
}

\author{
The promised land. Representations of Andalusia through tourism promotion \\ Javier Hernández Ramírez \\ Profesor Contratado Doctor. Departamento de Antropología Social. Universidad de Sevilla (España). \\ jhernan@us.es
}

\begin{abstract}
RESUMEN
Las campañas de marketing turístico contribuyen a modelar y difundir una imagen concreta de los destinos turísticos. En el estudio se analiza la evolución de los discursos promocionales sobre Andalucía como destino turístico desde 1928, año de año de creación del Patronato Nacional de Turismo, hasta la actualidad, con el enfoque aplicado por el gobierno autonómico andaluz. En el artículo se constata que los contenidos publicitarios han ido reflejando la propia evolución del sector turístico. En nuestros días la promoción turística institucional adopta nuevos lenguajes que ofrecen una representación de Andalucía que se acomoda a las expectativas de una demanda turística diversificada. Estos discursos conviven con visiones que coinciden con la imagen histórica y universal de esta tierra que persisten porque son del gusto del turista global.
\end{abstract}

\section{ABSTRACT}

Tourism marketing campaigns help to shape and publicize a specific image of tourist destinations. The study analyses the development of promotional speeches about Andalusia as a tourist destination since 1928, the year of the creation of the National Tourist Board, to the present, with the approach of the Andalusian regional government. The article notes that the advertising contents have been reflecting the development of the tourism sector. Today the tourism-promotion institution adopts new languages that offer a representation of Andalusia that will accommodate the expectations of a diversified tourist demand. These statements coexist with views that match the historic and universal image of this land that persist because they appeal to the taste of the global tourist.

\section{Imagen y publicidad turística}

El turismo es un fenómeno que intensifica la globalización y los contactos entre pueblos y culturas. Hasta su desarrollo a mediados del siglo XX, nunca antes en la historia de la humanidad se había producido un desplazamiento de personas tan enorme. Pero este nomadismo gigante (Urbain 1993) es mucho más que el movimiento ocioso de un creciente número de viajeros que genera profundas transformaciones económicas; es también un fenómeno de capital importancia pues contribuye decisivamente a modelar la imagen que se construye sobre los lugares receptores de viajeros. En este sentido, no sería exagerado afirmar que el turismo es hoy una de las actividades más determinantes en la producción de significados sobre la diversidad cultural, ya que ejerce una enorme influencia en las representaciones mentales y sociales sobre los otros.

La imagen del destino turístico interviene significativamente en el proceso de toma de decisiones que conduce a viajar, razón por la cual los promotores se esfuerzan en diseñar campañas publicitarias que pretenden cautivar y seducir a los turistas potenciales. En estas operaciones se construye una determinada imagen y se promociona el lugar con mensajes atractivos que resaltan la peculiaridad o alguna ventaja sobre los destinos competidores. Consiste normalmente en una recreación del destino 
que subraya determinadas cualidades, vela otros aspectos y proyecta un compendio simplificado o deformado de atributos de acuerdo con los deseos y demandas de la clientela turística de cada momento histórico.

En el caso andaluz la materia prima que da contenido a las campañas promocionales no surge de la nada, sino que bebe de una tradición sobre lo andaluz que constituye la representación dominante que ha perdurado sobre esta tierra al menos desde que los escritores románticos la difundieron con éxito (Fourneau 1992). La eficacia simbólica de esta imagen consolidada explica la insistencia de la publicidad turística en un patrón que se reelabora permanentemente, pero que se nutre de modelos construidos en este periodo. Esta recurrencia permite hablar de un empecinamiento romántico en la imagen turística difundida que no es inmutable, puesto que el marketing se ha ido adaptando a las transformaciones socioculturales vividas, transmitiendo una imagen publicitaria ajustada a los nuevos gustos, expectativas y patrones de consumo.

Dada la importancia de la publicidad turística en la configuración de la imagen de Andalucía, este trabajo se centrará en el análisis de los discursos (textuales, fotográficos y audiovisuales) contenidos en las campañas publicitarias lanzadas fundamentalmente por las administraciones públicas. Aplicando una metodología que combina el análisis de contenido, semiótico y diacrónico, en el estudio se muestran las continuidades y los cambios producidos en las imágenes proyectadas sobre Andalucía por las instituciones públicas especializadas en la actividad turística. Se concluye con una reflexión sobre las repercusiones de dichas imágenes en la población andaluza y cómo afectan a las expectativas y percepciones que los turistas desarrollan sobre el destino durante la experiencia del viaje y una vez que han regresado a su lugar de origen.

\section{Una propuesta metodológica para el análisis de la publicidad turística}

En la investigación se ha analizado la imagen proyectada de Andalucía desde 1928 hasta la actualidad a través del estudio de la publicidad institucional promovida por las administraciones públicas estatales, autonómicas, provinciales y locales en formato de anuncio y cartel. Para el análisis de la documentación se han empleado dos técnicas de investigación: el análisis de contenido y la interpretación semiótica. Ambas herramientas son complementarias, pues integran el enfoque cuantitativo con el cualitativo o semiológico. Las dos técnicas se enriquecen con una perspectiva diacrónica que permite determinar las continuidades y los cambios de las imágenes proyectadas, considerando tres etapas fundamentales: una primera que se desarrolla en el periodo 1928-50, que se ha denominado prefordista; una segunda fase fordista que abarca la etapa 1951-77; y una tercera posfordista que se inicia en 1978 y llega hasta nuestros días.

El análisis de contenido de 510 imágenes incluidas en 467 anuncios y carteles emitidos por organismos responsables de turismo de las administraciones públicas ha permitido establecer una clasificación que ha tomado como principales variables los espacios y los actores sociales. En términos espaciales se han determinado cuatro categorías: zonas exclusivamente turísticas; escenarios del patrimonio histórico; lugares del patrimonio etnológico; y, por último, espacios naturales. La presencia o ausencia de sujetos en los anuncios constituye la segunda variable independiente. En este sentido, se han definido también cuatro tipos. Son los siguientes: imágenes que representan espacios sin personas; áreas en las que sólo aparecen turistas; lugares donde los nativos son los únicos protagonistas de las instantáneas y, por último, anuncios que muestran a anfitriones e invitados (Smith 1992). Tal como refleja el cuadro 1, el cruce de estas variables y categorías ha dado como resultado dieciséis tipos de representaciones turísticas. 


\begin{tabular}{|c|c|c|c|c|c|}
\hline \multirow{2}{*}{\multicolumn{2}{|c|}{$\begin{array}{l}\text { Cruce de categorias de } \\
\text { análisis }\end{array}$}} & \multicolumn{4}{|c|}{ ESPACIOS } \\
\hline & & Zonas turisticas & $\begin{array}{c}\text { Escenarios del } \\
\text { patrimonio }\end{array}$ & $\begin{array}{l}\text { Lugares del } \\
\text { patrimonio }\end{array}$ & $\begin{array}{l}\text { Espacios } \\
\text { naturales }\end{array}$ \\
\hline \multirow{7}{*}{$\begin{array}{l}\mathrm{A} \\
\mathrm{C} \\
\mathrm{T} \\
\mathrm{O} \\
\mathrm{R} \\
\mathrm{E}\end{array}$} & Sin personas & 1 & 2 & 3 & 4 \\
\hline & Sólo & 5 & 6 & 7 & 8 \\
\hline & aparecen & & & & \\
\hline & turistas & & & & \\
\hline & Nativos & 9 & 10 & 11 & 12 \\
\hline & únicos & & & & \\
\hline & protagonistas & & & & \\
\hline $\mathrm{s}$ & Turistas y & 13 & 14 & 15 & 16 \\
\hline
\end{tabular}

Cuadro 1. Variables centrales del análisis de contenido

La sistematización de la suma de imágenes recopiladas ha constituido el corpus sobre el que se ha efectuado el posterior análisis semiótico, cuyo objetivo central es interpretar el significado implícito de los anuncios. Siguiendo la tradición semiológica de Barthes (1997) y Victoroff (1980), que sostienen que existe una gramática publicitaria, con el análisis semiótico se leen los argumentos presentes en la publicidad, es decir, se identifican y relacionan los discursos que subyacen en cada imagen visual y lingüística como códigos de un lenguaje. Esta metodología es de especial utilidad para interpretar la narrativa presente en los anuncios, descifrar el mensaje simbólico (o connotativo) que aparece impreso en el mensaje literal (o denotativo) y determinar los significados y objetivos publicitarios.

En definitiva, en este trabajo se hace una apuesta metodológica que procede a la combinación del análisis de contenido con el semiótico para el estudio de las representaciones turísticas. El enfoque cuantitativo permite establecer qué mensajes son transmitidos con más frecuencia y, de este modo, establecer tipologías. El semiótico completa el análisis determinando los significados y objetivos que subyacen en la publicidad. Ambos enfoques, se enriquecen con la perspectiva diacrónica que permite conocer las imágenes turísticas que han prevalecido en cada etapa histórica. Este conjunto de técnicas constituye una metodología que nos aproxima a un cabal conocimiento de la representación turística de Andalucía.

\section{Análisis de contenido de las representaciones turísticas}

Atendiendo a la variable espacial, el estudio de la documentación revela que en todo el periodo analizado prevalece una imagen de Andalucía como espacio marcado por el peso de las tradiciones y la historia, ya que los registros que versan sobre estas dos temáticas representan el 64\% de la muestra (36,2\% y $27,2 \%$ respectivamente). En segundo lugar destacan aquellas representaciones en las que Andalucía se presenta como tierra idónea para el disfrute de unas vacaciones convencionales orientadas al ocio hedonista, especialmente, de sol y playa (20,9\%), y son menos abundantes los anuncios que promocionan espacios que se presentan como naturales $(15,4 \%)$.

Respecto a la segunda variable, la que se centra en los actores, es significativo señalar que en nada menos que el 50\% de las imágenes de la muestra son representados escenarios solitarios, sin actividad humana. En relación a los anuncios y carteles en los que aparecen personas es interesante resaltar que, a lo largo de toda la historia de la publicidad turística institucional, los turistas aparecen en mayor número de instantáneas que los nativos (27,2 vs. 19,2), y que es casi insólita la publicidad en la que se produce interacción entre visitantes y población autóctona, pues apenas suponen el 3\% de todos los registros analizados.

El cruce de las dos variables (espacios y actores) permite profundizar en los resultados y acercarnos con mayor precisión a la imagen proyectada de Andalucía. Si se atiende a los valores porcentuales de participación de los sujetos en los cuatro tipos de espacios, se observa que aquellos anuncios y carteles que muestran bienes pertenecientes al patrimonio histórico concentran el mayor porcentaje de espacios 
de toda la muestra en los que la instantánea muestra al bien sin actividad humana (41\%). Esta imagen solitaria contrasta con las zonas especializadas en servicios turísticos donde se encuentra la mayor proporción de turistas de la muestra $(53,2 \%)$ y con los anuncios que toman como reclamo manifestaciones culturales y lugares tradicionales donde es la población autóctona la que toma el protagonismo (81\%), siendo esta modalidad de publicidad la que muestra además un mayo número anuncios que presentan a turistas y nativos simultáneamente. Por su parte, los entornos naturales son representados sin personas o con turistas como únicos actores sociales (nunca nativos).

\section{Interpretación de la narrativa publicitaria}

Podría decirse que en la publicidad turística existe un lenguaje. El conocimiento de los elementos y códigos que conforman esta gramática permite la comprensión de la imagen que se desea proyectar y la evolución de la misma. En este sentido, nada es gratuito ni arbitrario en la publicidad. Tanto el texto como lo que se representa visualmente en los anuncios está cargado de connotaciones, cuyo sentido y variabilidad pueden ser interpretados mediante el análisis semiótico. La investigación revela que en los anuncios la fuerza y expresividad de la imagen visual supera a la del texto escrito. Esto se debe a que como ya apuntó Urry 1992- la experiencia turística es, ante todo, visual y que esta experiencia comienza con la visión de fotografías, documentales y películas antes de la partida (Hernández-Ramírez 2004). Por ello, la función esencial del mensaje publicitario la asume normalmente la iconografía, que se convierte en el principal instrumento de seducción (Rodríguez García 2008).

Siguiendo el esquema clasificatorio de los anuncios aplicado en el análisis de contenido (actores y espacios), con el enfoque semiótico se tratan de explicar los discursos contenidos en los patrones visuales más recurrentes. En este sentido, se ha constatado que la presencia o ausencia de sujetos en las imágenes no es casual, sino intencional, ya que se utiliza para transmitir determinados contenidos publicitarios, porque las personas que aparecen en los anuncios, sus roles sociales y las actividades que desempeñan son códigos de la gramática visual publicitaria. En el caso del patrimonio histórico no es un capricho de autor presentar el bien monumental en lugares solitarios sin personas de ningún tipo (ni turistas ni nativos). Tampoco es un simple recurso estético que los elementos del pasado sean retratados fuera de su contexto, ajenos a cualquier elemento que revele la realidad contemporánea. La soledad del monumento tan recurrente en la historia de la publicidad turística es una técnica que persigue crear una ficción de quietud y atemporalidad, mostrando lugares callados, sin bullicio, carentes de signos que evidencien dinamismo y el paso del tiempo como si éste se hubiese detenido. De este modo se incita a viajar a un lugar situado en el pasado, pleno de memoria, donde el monumento, depurado de todas las impurezas sociales que contaminan su esencia, es convertido en objeto para la admiración, la imaginación histórica, la certificación de mitos, la contemplación y, en definitiva, para el diálogo con el turista.

Las técnicas fotográficas empleadas intervienen también en este sistema de comunicación visual influyendo en la percepción subjetiva por su capacidad para transmitir una imagen de eterna quietud. Entre las técnicas más habituales destacan el recurso al encuadre, que permite recortar el campo visual y aumentar el protagonismo de los monumentos; el plano contrapicado, que engrandece el objeto fotografiado; o la solemnidad del blanco y negro, que intensifica la impresión de antigüedad. Este conjunto de técnicas genera una determinada atmósfera donde domina el pasado sobre el presente.

A diferencia de la categoría anterior, los anuncios que representan manifestaciones del patrimonio etnológico, especialmente si nos referimos a acciones simbólicas festivas, son los que muestran con mayor frecuencia a la población autóctona y es en ellos donde mejor puede analizarse la visión que se ofrece de los andaluces. Aunque existen variaciones en el tratamiento de los nativos a lo largo de historia publicitaria, evolucionando de las escenas pintorescas y costumbristas a otras que persiguen impactar emocionalmente en el receptor, se advierte como constante el deseo de mostrar un universo distinto, pasional, alejado de la razón y anclado en una tradición atávica. Con ello se trata de reforzar el argumento implícito de la autenticidad y singularidad cultural con el que se pretende atraer a un 
En sentido contrario los anuncios que representan zonas turísticas dan un mayor protagonismo a los visitantes. Este predominio de los turistas obedece al interés de la publicidad por mostrar que estos espacios diseñados para el placer están a disposición del cliente potencial. En esta tipología de anuncios también se advierte una variación en el tratamiento de los actores a lo largo del tiempo, sin embargo, es constante tanto la presencia destacada de los turistas como la proyección de estos lugares como espacios al servicio de sus deseos. Quizás por ello la población autóctona apenas aparece y cuando así ocurre casi siempre es para interpretar roles en actitud de servicio, subrayando el objetivo implícito que muestra Andalucía como un paraíso del placer para los turistas, donde pueden encontrar los más avanzados servicios, los productos más modernos y una población atenta, de carácter amable y hospitalario.

Por su parte, los anuncios que promocionan la naturaleza muestran lugares vacíos o con la presencia de turistas, nunca población autóctona. Obviamente, esta ausencia de nativos es intencionada, porque se corresponde con una determinada visión occidental de la naturaleza entendida como espacio puro, cuya existencia y riqueza se explica precisamente por su aislamiento de toda actividad humana. La intencionalidad es atraer a turistas amantes del medio ambiente, por lo que se oferta la visita a reductos de la naturaleza virgen, indómita, que no han sufrido impactos antrópicos. En otras palabras, ofrecen excepciones naturales en un mundo que se percibe deteriorado y en riesgo. Para ello se recurre a planos panorámicos y cenitales capaces de representar escenarios a un nivel sobrehumano al profundizar y/o ampliar la panorámica o a la imagen de turistas que contemplan absortos la inmensidad de un territorio o practican actividades, generando la sensación de que es un espacio para la conquista. Esta geografía imaginada no se corresponde con los paisajes culturales andaluces, cuya característica principal es la de constituir territorios modelados históricamente por la actividad humana.

\section{Continuidades en la imagen proyectada}

Respecto del patrimonio histórico son constantes en la publicidad turística emitida por los organismos públicos la sobre-representación de los bienes monumentales, lo que contrasta con un escaso énfasis sobre el rico patrimonio mueble andaluz, el cual aparece excepcionalmente. Esta sub-representación también afecta al legado histórico de amplias zonas de Andalucía, cuyo repertorio de bienes es silenciado por la publicidad institucional, lo que también contrasta con la sobreexplotación de imágenes de determinados bienes que aparecen hasta la saciedad. En este sentido, un buen ejemplo de empecinamiento romántico y del poder de las imágenes universales en la construcción de las representaciones de Andalucía es la centralidad que tiene el patrimonio histórico heredado del periodo de Al-Andalus. A pesar del indiscutible dominio del estilo barroco, existe una sobre-representación de los monumentos de Al Andalus en la propaganda turística, ya sean carteles, medios audiovisuales o guías (Ruiz y otros 2006). Prueba de ello es que el 33,8\% de las imágenes clasificadas en la categoría de patrimonio histórico corresponden a monumentos, obras de arte y artesanías de tiempos de la presencia musulmana en Andalucía. El fenómeno refleja la persistencia de la visión difundida por la obra de los viajeros románticos que sitúa a Andalucía en un lugar liminar entre occidente y oriente; en una tierra marcada aún por su herencia oriental. Esta visión orientalizante, que López Ontiveros denomina maurofilia, supone mucho más que una excesiva proyección de los testimonios del pasado de Al Andalus, pues implica "interpretar todo el paisaje humano andaluz en función del esplendor musulmán y su posterior decadencia" (2001). Por su singularidad y por su capacidad para atraer a un sector de turistas interesados por el pasado andalusí y por esta mirada romántica que orientaliza a Andalucía, el marketing funciona aquí como correa de transmisión de esta imagen universal, reforzándola y contribuyendo a la exotización (Méndez y otros 2010). Otra constante es la descontextualización y desnaturalización del patrimonio histórico. Los autores de las instantáneas se esfuerzan en retratar los elementos del pasado evitando cualquier signo de la realidad contemporánea. Toda acción y toda referencia al presente quedan suprimidas creando una ficción de placidez e intemporalidad, presentando el patrimonio histórico al margen del universo cultural en el que se inserta, fuera de la experiencia 
cotidiana y de los valores simbólicos autóctonos que atesoran los bienes culturales. Por ello, raramente se muestra a la población local en torno a los monumentos, los cuales aparecen solitarios, para evocar con fuerza un pasado imaginario y, otras veces, acompañados de turistas neorrománticos que, ajenos al momento histórico presente, los admiran y se impregnan de su espíritu, viajando en el tiempo.

La promoción del turismo interior también utiliza este recurso en el que el tiempo parece haberse detenido. En todas las representaciones subyace implícitamente la idea de que la huella de la historia es omnipresente y marca el ser andaluz. Como constante, las pequeñas localidades rurales tienen un especial protagonismo en la publicidad, creando la quimera de que Andalucía es un territorio campesino, ajeno a la modernidad. Son pueblos estetizados, pintorescos, congelados en el tiempo, ideales para su contemplación e idealizados como una arcadia donde reina la sencillez, la paz y una forma de vida armónica en contacto con la naturaleza. A ello contribuye la presentación panorámica de totalidades urbanas que genera la sensación de que los pueblos andaluces no solo viven atrasados sino aislados, fuera de todo tiempo y lugar, sin conexiones con el exterior. Obviamente lo que se construye es una imagen turística que se ajusta a los deseos de los visitantes que buscan un inexistente paraíso rousseaniano. Pero esta representación tiene poco que ver con la intensa vida que suele existir en el interior de los pueblos ni con el sistema de ciudades que articula territorialmente a las poblaciones grandes, medianas y pequeñas de la geografía andaluza. También existen claras continuidades en la representación de los espacios naturales. Aquí se recurre a la presentación de paisajes solitarios en los que, cuando aparece alguien, es el turista, en actitud contemplativa y de comunicación con la naturaleza o de disfrute, descansando o practicando actividades recreativas y deportivas. Raramente aparecen territorios transformados por el hombre, subrayando nuevamente que el tiempo se ha detenido. Esta representación del medio ambiente como espacio natural sin transformar difícilmente se corresponde con la realidad de una tierra que, si tiene una característica definitoria, es su humanización, por lo que más que de espacios naturales habría que hablar de paisajes culturales conformados por el hombre. Ejemplo paradigmático de esta interrelación armónica serían las dehesas cuyos valores ecológicos se derivan precisamente de la intervención humana. Pero también habría que resaltar los impactos que el turismo y la urbanización han producido en el medio ambiente, lo que contrasta con la imagen presentada en la publicidad. Sirva como botón de muestra las playas, presentadas en las imágenes promocionales como espacios vírgenes, aislados y sostenibles, aunque en realidad la franja litoral, que constituye tan sólo el $10 \%$ del territorio, concentra una tercera parte de la población total de la comunidad autónoma y las costas se transforman aceleradamente ante la moda de los paseos marítimos y la proliferación de puertos deportivos que siguen creciendo.

El tratamiento de la arquitectura tradicional es también repetitivo. El estudio constata la recreación de patrones constructivos: abundan los anuncios con la imagen romántica de cuidados patios, rejas, azulejos, fachadas encaladas, balcones con macetas e íntimas callejuelas, así como la reproducción de determinados barrios típicos sobre todo de Córdoba y Sevilla, pero se aprecian significativas ausencias de estilos, tipos constructivos y territorios completos que también son propios de Andalucía. Asimismo se ignora la arquitectura residencial vernácula tanto rural como urbana de muchas zonas, así como los inmuebles tradicionales relacionados con la producción agropecuaria, artesanal o industrial y los espacios de la sociabilidad. Frente a la aparente armonía cromática que se ha querido resaltar como propia de la arquitectura vernácula andaluza, hay que confrontar la realidad de un sobresaliente gusto por los detalles ornamentales; frente a la homogeneidad urbanística que remarca una imagen tópica que simplifica la diversidad existente habría que contraponer una rica diversidad de estilos y formas. El resultado es la reproducción de unos clichés de tipismo que se traducen en la caricaturización folklorizada de la arquitectura vernácula (Agudo 2002).

Este patrón se reproduce en otras manifestaciones propias del patrimonio etnológico. Las fiestas y romerías tan características de la identidad andaluza son objeto de la publicidad turística, sin embargo, también en esta modalidad hallamos continuidades como la redundancia de determinadas acciones simbólicas festivas propias del valle del Guadalquivir y el occidente andaluz y la sub-representación y exclusión de determinadas manifestaciones y de amplios territorios. Asimismo, frente al dinamismo consustancial de los rituales, las fiestas son mostradas como acciones que se desarrollan en un espacio detenido, donde nada cambia, ni los aspectos formales y estéticos ni la actitud de los nativos, que 
parecen estar sumidos en un ethos cultural marcado por un extremado inmovilismo. Es una visión que remarca los aspectos más exóticos, lúdicos y excepcionales de las fiestas, mostrándolas desconectadas de la vida social y sus cambios, como celebraciones que se repiten mecánicamente por imperativo de una tradición irreflexiva e irracional.

También la gastronomía se presenta invariable y homogénea. Pese a la diversidad del patrimonio alimentario andaluz son sobre-representadas las tapas y un reducido repertorio de alimentos y bebidas que resumen toda la gastronomía en unos pocos elementos. En ningún caso encontramos referencias a los significados culturales que tiene la comida para los andaluces, los cuales sólo aparecen como camareros o complacientes acompañantes al servicio del turismo. Son inexistentes los carteles que subrayen el importante papel de la gastronomía en rituales festivos y en otros acontecimientos que hacen del comer y el beber un factor indispensable para la construcción y continuidad de las distintas comunidades simbólicas andaluzas.

En su conjunto las tradiciones son mostradas como una manifestación de la diferencia, como fenómenos exóticos y extraordinarios con respecto al mundo cotidiano del turista. Estos recursos permiten transformar al conjunto del patrimonio etnológico en un fascinante producto turístico, que se oferta como espectáculo sin consistencia histórica, antropológica y social. No existe ningún interés en mostrar los usos sociales del patrimonio, los modos de vida de los pueblos. El lugar es, sobre todo, un producto idealizado y exotizado para la contemplación y la actividad turística.

En resumen, en todas las categorías espaciales contempladas se aprecian continuidades que modelan la imagen de Andalucía. En primer lugar, es una constante la sobreexplotación de temas, lo que conduce a generalizaciones y simplificaciones; en segundo, la sub-representación y exclusión de manifestaciones y de amplias zonas de la geografía andaluza, lo que supone un reduccionismo que oculta la diversidad y riqueza de la cultura; y en tercero, la descontextualización de los bienes y expresiones tradicionales de la vida social. El resultado es la proyección de una representación que conecta e intensifica el imaginario colectivo forjado desde el romanticismo. La justificación desde la óptica del marketing es contundente: esta imagen homogénea y simplificada de la realidad ha demostrado su eficacia como poderoso instrumento de seducción.

\section{Cambios en la imagen difundida}

Dado el espectacular crecimiento del turismo en las últimas décadas, la incidencia del fenómeno en la conformación de la imagen de los destinos es mucho mayor que en etapas anteriores de turismo fordista $\mathrm{u}$ organizado. Esto ha supuesto cambios significativos en la imagen proyectada. Durante la etapa de turismo fordista la estrategia promocional se centraba en ofertar territorios y temas concretos. Podría decirse que se promocionaba la parte por el todo, es decir, que los escenarios retratados se limitaban a un Mediterráneo exotizado, pintorescos pueblos aislados, monumentos orientales e inalterables tradiciones. Con esta mirada no se pretendía transmitir una representación global ni objetiva del lugar, sino mostrar un territorio propicio al placer y el exotismo de acuerdo con los deseos y expectativas de los turistas de masas para su tiempo de vacaciones. Todo lo demás quedaba fuera.

El posfordismo implica un cambio importante, porque se dirige a diversidad de turistas. Frente al consumidor homogéneo de la etapa anterior, en el postfordismo la oferta se diversifica y amplía, comercializando sensaciones y emociones en cualquier momento y lugar y penetrando en muchos rincones de la realidad anteriormente inexplorados. Este cambio de la oferta no podría explicarse exclusivamente como una inteligente operación de mercadotecnia, sino que tiene su fundamento en transformaciones sociales, políticas y económicas, las cuales inciden directamente en la reorientación de la estrategia. Todo ello se ha traducido en una sustantiva modificación de los contenidos y significados de la imagen turística de Andalucía y en una mirada renovada sobre su realidad.

Respecto al tratamiento de la variable espacial, se comprueba que la oferta turística ha sufrido cambios interesantes que están relacionados con las pautas de consumo imperantes. En primer lugar se aprecia 
una oferta más diversificada. Prueba de ello es el incremento de los anuncios sobre espacios naturales. Aunque esta categoría continúa ocupando el último lugar en cuanto a número, se observa un crecimiento de la oferta de una imagen novedosa que presenta determinados espacios emblemáticos andaluces como verdaderos paraísos naturales idóneos para la práctica del turismo rural, deportivo o de aventura. La comparación del volumen de anuncios de la actual etapa con la anterior así lo confirma, ya que el $19,5 \%$ de las imágenes pertenecen a la categoría espacio natural mientras que en el periodo fordista apenas se superaba el 5\%. Paralelamente se produce un ligerísimo descenso de la oferta de imágenes relativas al patrimonio histórico y las zonas turísticas con respecto a la etapa precedente. Todos estos cambios manifiestan una evolución de la imagen turística de Andalucía en la que se va definiendo una oferta más proporcionada, aunque se mantiene el predominio de una visión que la representa como territorio marcado por la historia y las tradiciones.

La diversificación de los temas anunciados también es temática y de tratamiento. Esto se aprecia en el patrimonio histórico donde se ha ampliado el repertorio de bienes monumentales que son difundidos por la propaganda turística. A ello contribuye sin lugar a dudas el reconocimiento por parte de administraciones internacionales del valor patrimonial de nuevos bienes y su inclusión en catálogos, especialmente si son administrados por la UNESCO como la Lista del Patrimonio Mundial. Esta ampliación refleja nuevamente la adecuación de la imagen de Andalucía a los gustos y expectativas de un importante sector de turistas interesados en los enclaves reconocidos internacionalmente por esta institución (Marcos 2010 y Velasco 2012). Con esta expansión de la oferta monumental se ha superado en parte la inercia romántica, aunque persiste claramente la visión orientalizante de Andalucía que la singulariza en el mercado turístico.

También se observan cambios en el tratamiento de las manifestaciones tradicionales. Aunque persiste ea insistencia romántica, las manifestaciones culturales pasan de ser presentadas como tradiciones autóctonas folclóricas y pintorescas a ser mostradas como singulares formas de expresión artística con valores universales. Esta evolución se encuadra en un marco más general de paulatina transformación y revalorización de las costumbres como patrimonio cultural y se ajusta a nuevas tendencias turísticas que demandan encontrar en otras culturas vestigios de una presunta autenticidad humana de valores universales.

Los actores como segunda categoría de análisis también presentan interesantes cambios. En este sentido, se produce un crecimiento porcentual de las representaciones de turistas y un paralelo descenso de las que registran a población autóctona. Pero los cambios no son solo cuantitativos sino también cualitativos. En este sentido, la publicidad adopta estilos comunicativos innovadores que recurren a los sentimientos y las emociones como reclamo, orientándose al individuo concreto, tomando en cuenta su idiosincrasia, ideología, gustos y expectativas. Es un marketing personalizado o relacional que refleja como señala Lipovetsky 2002- el eclipse del tiempo de la persuasión masiva y el nacimiento de una publicidad hiperdiferenciada. Esto se traduce en una mayor presencia de turistas como protagonistas de las imágenes y en un tratamiento diferenciado según las expectativas detectadas por la investigación de mercado. En este sentido y de acuerdo con sus actitudes en los anuncios se han identificado cuatro tipos de turistas: lúdicos, absortos, identificados e integrados. Cada uno no es arbitrario, sino que se corresponde con determinadas estrategias de marketing cuya intencionalidad es inducir a la visita a destinos patrimoniales de potenciales turistas pertenecientes a sectores sociales muy distintos.

El tratamiento de la población autóctona también se ha transformado en las últimas décadas. El análisis diacrónico permite comprobar el paso de una primera etapa en la que abundan las representaciones de escenas costumbristas, donde los nativos escenifican unos roles tópicos y repetitivos sobre todo en fiestas, a otras imágenes que persiguen impactar emocionalmente al receptor, conmoverle, sorprenderle, incluso implicarle, para así atraer su atención, provocar la fascinación ante la mirada de lo distinto que se presenta como pasional y penetrante.

En resumen, la publicidad actual sobre Andalucía emplea técnicas creativas innovadoras, semejantes a las utilizadas por las empresas más punteras del sector. Sus diseñadores conocen las motivaciones, deseos y expectativas de la diversidad de turistas, lo que les permite orientar su oferta hacia un 
tratamiento personalizado con los diversos tipos de clientes y de destinos. Pero estos cambios no modifican sustancialmente la imagen proyectada. Persiste una inercia romántica en las representaciones difundidas, o dicho de otro modo, las imágenes turísticas inducidas sobre Andalucía están muy condicionadas por las universales, cuyos contenidos perduran obstinadamente, aunque dulcificados en sus aspectos más controvertidos porque podrían frenar la llegada de turistas. Se ha ganado en estética, aparecen nuevos temas, algunos tópicos han sido reconsiderados y elevados a la categoría de patrimonio cultural, se ha modificado y diversificado el tratamiento de la población nativa y de los turistas, pero se aprecia la repetición de un estereotipo que parece sintetizar y resumir a toda Andalucía: el que la muestra como una tierra ruralizada marcada por la tradición, el peso de la historia y la huella Al-Andalus. Esta recreación, acorde con patrones románticos, facilita la transformación de Andalucía en un escenario turístico, es decir, en mercancía comprensible y objetivada para su consumo. Y esto, que en principio responde a una estrategia de mercado, tiene consecuencias que van más allá del turismo, pues con las acciones promocionales se contribuye a la construcción de un imaginario colectivo (Borrueco 2007).

\section{Punto y seguido}

En el caso andaluz la imagen turística ofertada por la administración pública no se basa estrictamente en un análisis científico de la cultura e historia andaluza. Como resultado de este enfoque, la imagen que se oferta es una operación de mercadotecnia que trata de adecuarse a las demandas de consumo de distintos tipos de turistas para incrementar la demanda. Todo ello muestra que el marketing es estratégico y diseña la representación del lugar de acuerdo con el imaginario social de los turistas.

Posiblemente, si en el ámbito de la promoción la Administración impulsara la investigación de la realidad andaluza desde la perspectiva de la antropología, la historia, la sociología y la geografía, podrían luego ajustarse los discursos y representaciones a la misma, huyendo de visiones simplificadas. Asimismo, la adopción de una aproximación inclusiva en el diseño de la promoción y la marca turística (Morgan y Pritchard 2001: 296), donde los atributos y valores de los destinos fueran determinados por la propia población local, podría contribuir a la difusión publicitaria de rasgos culturales y patrimoniales relevantes, representativos y alejados de los estereotipos.

Y lo dicho no es baladí, porque las imágenes inducidas trascienden de su función comercial de atraer turistas. En su conjunto son interpretaciones de la realidad que construyen realidad. Para los turistas dichas imágenes funcionan como cristales desde los que se mira los escenarios que visitan, pero para los andaluces actúan como espejos en los que se reconocen.

\section{Bibliografía}

Agudo, Juan

2002 "Arquitectura doméstica tradicional andaluza. Diversidad y riqueza", Arquitectura doméstica tradicional andaluza. Sevilla, Junta de Andalucía: 7-21.

Barthes, Roland

1997 Mitologías. México, Siglo XXI Editores.

Bindi, Leticia

2009 "Imaginar un país. Medios, producción de la localidad y representaciones de la tradición", Gazeta de Antropología, 25 (1). 
Borrueco, María A. (coord.)

2007 El lenguaje publicitario en el turismo. Consejería de Turismo, Comercio y Deporte, Junta de Andalucía.

Fourneau, Francis

1992 "Viajeros en Andalucía y representaciones turísticas de un cierto paisaje mediterráneo", Paisaje Mediterráneo. Milán, Electa.

Galí, Nuria

2005 "La humanización de las imágenes emitidas por la publicidad de los destinos monumentales: el caso de Girona", Pasos, vol. 3, nº 2: 273-281.

Garrido, Manuel

2005 "La publicidad turística en Andalucía (2002-2005): Andalucía sólo hay una. La tuya vs. Andalucía te quiere", Questiones Publicitarias, Revista Internacional de Comunicación y Publicidad, vol. 1, n 10: 77-97.

Hernández-Ramírez, Javier

2008 La imagen de Andalucía en el turismo. Sevilla, Centro de Estudios Andaluces.

2004 "Turismo inducido. La configuración de la imagen turística de Sevilla a través del cine comercial", Congreso Internacional: Patrimonio, Desarrollo Rural y Turismo en el siglo XXI, vol. II: 503-515. Sevilla, Escuela Universitaria Francisco Maldonado de Osuna.

Lash, Scott (y John Urry)

1998 Economías de signos y espacio. Sobre el capitalismo de la posorganización. Buenos Aires, Amorrortu Editores.

Lipovetsky, Gilles

2002 La era del vacío. Barcelona, Anagrama.

López Ontiveros, Antonio

2001 "Caracterización geográfica de Andalucía según la literatura viajera de los siglos XVIII y XIX", Ería, no 54-55: 7-51.

Marcos Arévalo, Javier

2010 "El patrimonio como representación colectiva. La intangibilidad de los bienes culturales", Gazeta de Antropología, nº 26 (1).

Méndez, Luis (Rocío Plaza y Antonio Zoido)

2010 Viaje a un Oriente Europeo. Patrimonio y Turismo en Andalucía (1800-1929). Sevilla, Centro de Estudios Andaluces.

Morgan, Nigel J. (y Annethe Pritchard)

2001 Advertising in Tourism and Leisure. Oxford, Butterworth-Heinemann.

Noogués Pedregal, Antonio Miguel

2008 "Poder político local y urbanismo en entornos turísticos. La mediación del espacio turístico en la producción de significados", Gazeta de Antropología, nº 24 (2).

Rodríguez García, Sonia Ester

2008 "Connotación y persuasión en la imagen publicitaria", Gazeta de Antropología, n 24 (2).

Ruiz, Fernando y otros

2006 La imagen de Andalucía en las guías turísticas. Málaga, Editorial Sarriá.

Smith, Valene (coord.) 
1989 Anfitriones e invitados. Antropología del turismo. Madrid, Endymion.

Urbain, Jean-Didier

1993 El idiota que viaja. Madrid, Endymion.

Urry, John

2002 The tourist gaze. London, Sage.

Velasco, Honorio

2012 "De patrimonios culturales y sus categorías", Gazeta de Antropología, nº 28 (3).

Victoroff, David

1980 La publicidad y la imagen. Barcelona, Gustavo Gili. 